\title{
Correction to: A win-win situation: Does familiarity with a social robot modulate feedback monitoring and learning?
}

\author{
Abdulaziz Abubshait $^{1,2} \cdot$ Paul J. Beatty $^{1} \cdot$ Craig G. McDonald $^{1} \cdot$ Cameron D. Hassall ${ }^{3}$ - Olav E. Krigolson ${ }^{4} \cdot$ Eva Wiese $^{1,5}$ \\ Published online: 3 May 2021 \\ (C) The Psychonomic Society, Inc. 2021
}

\section{Correction to: Cognitive, Affective, \& Behavioral Neuroscience https://doi.org/10.3758/s13415-021-00895-9}

This article was originally published electronically on the publisher's internet portal (currently SpringerLink) on April 6, 2021 with open access.

With the author(s)' decision to step back from Open Choice, the copyright of the article changed on April 12, 2021 to (C) The Psychonomic Society, Inc. 2021 and the article is forthwith distributed under the terms of copyright.

Publisher's note Springer Nature remains neutral with regard to jurisdictional claims in published maps and institutional affiliations.

The online version of the original article can be found at https://doi.org/ 10.3758/s13415-021-00895-9

Abdulaziz Abubshait

Abdulaziz.Abubshait@iit.it

1 George Mason University, Fairfax, VA, USA

2 Italian Institute of Technology, Genova, Italy

3 University of Oxford, Oxford, UK

4 Department of Psychology, University of Victoria, Victoria, BC, Canada

5 Institute of Psychology and Ergonomics, Berlin Institute of Technology, Berlin, Germany 